\title{
Structural and Optical Property of High Quality GaN Thin Film on Si with ZnO Buffer Layer
}

\author{
Jianting He*, Shulian Yang, Qinqin Wei \\ College of Electrics and Electronics Engineering, Shandong University of Technology, Zibo, China
}

\section{Email address:}

hejianting@sdut.edu.cn (Jianting He)

${ }^{*}$ Corresponding author

\section{To cite this article:}

Jianting He, Shulian Yang, Qinqin Wei. Structural and Optical Property of High Quality GaN Thin Film on Si with ZnO Buffer Layer. Journal of Photonic Materials and Technology. Vol. 5, No. 1, 2019, pp. 1-4. doi: 10.11648/j.jmpt.20190501.11

Received: January 29, 2019; Accepted: March 17, 2019; Published: April 8, 2019

\begin{abstract}
A method was applied to improve the crystallization quality of $\mathrm{GaN}$. $\mathrm{ZnO}$ thin films were deposited on n-Si (111) at $600^{\circ} \mathrm{C}$ by pulsed laser deposition (PLD), and $\mathrm{GaN}$ thin films were grown on $\mathrm{Si}$ or $\mathrm{ZnO} / \mathrm{Si}$ by R. F. magnetron sputtering system. Several $\mathrm{GaN}$ films were prepared with $\mathrm{ZnO}$ as buffer layer without annealing, with $\mathrm{ZnO}$ as buffer layer annealed at $850^{\circ} \mathrm{C}, 900^{\circ} \mathrm{C}$ and $950^{\circ} \mathrm{C}$ and with no buffer layer annealed at $950^{\circ} \mathrm{C}$, respectively. The crystallization, optical property and morphology of all GaN films prepared were studied by X-ray diffraction (XRD), Fourier transform infrared spectrophotometer (FTIR), photoluminescence (PL) and scanning electron microscope (SEM). The results show that $\mathrm{ZnO}$ buffer layer plays an important role in improving the crystallization quality of GaN.
\end{abstract}

Keywords: Structure Property, Optical Property, Crystallization, ZnO Buffer Layer, GaN Film

\section{Introduction}

The third-generation semiconductor material represented by gallium nitride $(\mathrm{GaN})$ is an excellent III-V group elements compound semiconductor material, with a band gap width of $3.4 \mathrm{ev}$ and exciton binding energy of $20 \mathrm{meV}$ at room temperature [1]. Due to the fact that the light transition probability of direct band-gap material has an order of magnitude higher than that of the indirect band-gap material, coupled with its wide gap, $\mathrm{GaN}$ is the preferred material for the preparation of blue-green light emitting diode (LED) and laser diode (LD) photoelectric devices [2]. In addition, $\mathrm{GaN}$ is very suitable for making high-temperature, high-frequency and high-power electronic devices due to its high saturation velocity of electron drift, small dielectric constant, good thermal conductivity and good thermal stability [3].

Si has many advantages as the substrate of GaN material, such as better crystallinity, large size, low cost, easy processing, good electrical conductivity, thermal conductivity and thermal stability and easy to make integrated circuits. But it is difficult to grow high-quality GaN epitaxial layer on Si substrate since there is a huge lattice mismatch and thermal mismatch between $\mathrm{GaN}$ and $\mathrm{Si}$, this will cause cracks in the $\mathrm{GaN}$ epitaxial layer during the cooling process [4]. Because $\mathrm{ZnO}$ and $\mathrm{GaN}$ have the same lattice hexagonal wurtzite structure and the little lattice mismatch and thermal mismatch, $\mathrm{ZnO}$ can be used as a buffer layer for the growth of $\mathrm{GaN}$ thin films [5]. In our experiments, high quality $\mathrm{ZnO}$ buffer layer was firstly grown on Si substrate at $600^{\circ} \mathrm{C}$ by pulsed laser deposition, and then $\mathrm{GaN}$ was epitaxial grown by magnetron sputtering method and annealed. The results showed that $\mathrm{ZnO}$ buffer layer greatly improved the crystallization quality of GaN.

\section{Experiment}

The deposition of $\mathrm{ZnO}$ films was carried out by PLD. The laser device we used is $\mathrm{Nd}$ : YAG, with output wavelength of $1064 \mathrm{~nm}$ and single-pulse energy of $208 \mathrm{~mJ}$. The laser spot area hitting the target is $0.43 \mathrm{~mm}^{2}$, producing energy density of $48 \mathrm{~mJ} / \mathrm{cm}^{2}$, with frequency of $10 \mathrm{~Hz}$ and pulse width of $10 \mathrm{~ns}$. The solid target is sintered with high purity $\mathrm{ZnO}$ (99.99\%) which deposited on n-Si (111) substrate. The PLD system was vacuumized to $1.2 \times 10^{-4} \mathrm{~Pa}$, and then was filled with $0.13 \mathrm{~Pa}$ high purity oxygen $(99.999 \%)$. While the substrate temperature was heated to $600^{\circ} \mathrm{C}$, the $\mathrm{ZnO}$ target was ablated by focused pulse laser beam that passed through the optical window of system chamber. The deposition finished after 
$15 \mathrm{~min}$, after which $\mathrm{ZnO} / \mathrm{Si}$ sample was prepared.

$\mathrm{GaN}$ thin films were grown by sputtering GaN target with $\mathrm{ZnO}$ as buffer layer using JCK-500A RF magnetron sputtering system. The sintered GaN target has a purity of $99.999 \%$. The system vacuum was $3.2 \times 10^{-4} \mathrm{~Pa}$. When the system was working, high-purity argon gas was applied and the partial pressure is $2 \mathrm{~Pa}$. The sputtering power was $150 \mathrm{~W}$, and the sputtering time was $90 \mathrm{~min}$. Then the samples were annealed in an atmosphere of $\mathrm{NH}_{3}$ on the quartz boat at the temperature of $850^{\circ} \mathrm{C}, 900^{\circ} \mathrm{C}$ and $950^{\circ} \mathrm{C}$ for $15 \mathrm{~min}$, respectively. The crystal orientation and quality of $\mathrm{GaN} / \mathrm{ZnO} / \mathrm{Si}$ samples were examined by X-ray diffraction (XRD, Rigaku D/ max-rB $\mathrm{CuK} \alpha$ ), Fourier infrared absorption spectroscopy (FTIR, Tensor27), photoemission spectroscopy (FLS920) and scanning electron microscope (HITACHI S-570).

\section{Results and Discussions}

\section{1. $X R D$}

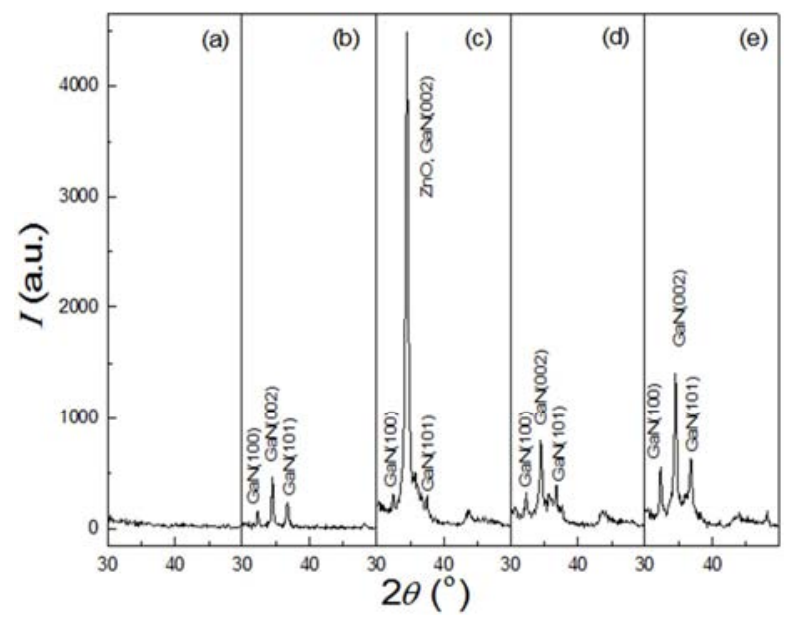

Figure 1. X-ray diffraction patterns of as-deposited GaN with ZnO buffer layer (a), GaN with no buffer layer at $950^{\circ} \mathrm{C}$ (b), GaN with ZnO buffer layer annealed at $850^{\circ} \mathrm{C}(\mathrm{c}), 900^{\circ} \mathrm{C}(\mathrm{d})$ and $950^{\circ} \mathrm{C}(\mathrm{e})$.

Figure 1 shows the X-ray diffraction patterns of GaN thin films under various condition. It can be seen from Figure 1(a) that $\mathrm{GaN}$ thin films sputtered with $\mathrm{ZnO}$ as buffer layer are still in an amorphous state when they are not annealed. In Figure $1(\mathrm{c}),(\mathrm{d})$ and (e), the diffraction peaks at $2 \theta=32.1^{\circ}, 34.4^{\circ}$, and $36.6^{\circ}$ correspond to the lattice plane of GaN (100), (002), and (101) respectively, indicating that $\mathrm{GaN}$ thin films are hexagonal wurtzite structures with lattice constants $a=0.318 \mathrm{~nm}$ and $\mathrm{c}=0.518 \mathrm{~nm}$. The diffraction peak of $\mathrm{GaN}$ (002) has the maximum intensity, indicating that $\mathrm{GaN}$ grows along the $\mathrm{c}$ axis which is a preferred orientation. It has been reported that $\mathrm{ZnO}$ starts to volatilize when it is annealed in $\mathrm{NH}_{3}$ at the temperature

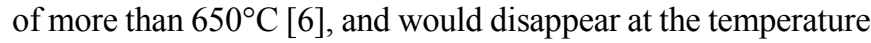
of $900^{\circ} \mathrm{C}$ [7]. If the annealing temperature does not exceed $900^{\circ} \mathrm{C}$, the $\mathrm{ZnO}$ buffer layer will not evaporate completely. Therefore, the (002) peak in Figure 1(c) can be ascribed to the superposition of the (002) planes of $\mathrm{ZnO}$ and $\mathrm{GaN}$ which have the similar lattice structure. Figure 1(d) and (e) show that GaN has the best crystallization quality at the annealing temperature of $950^{\circ} \mathrm{C}$ when all of the $\mathrm{ZnO}$ has volatilized, which means that the GaN grain size increases [8]. Compared with Figure 1(b), Figure 1(e) shows that $\mathrm{ZnO}$ buffer layer can improve the crystallization quality of GaN. This is because $\mathrm{ZnO}$ buffer layer effectively alleviates lattice mismatch and thermal mismatch, decreases internal stress and reduces dislocation density.

\subsection{FTIR}

As shown in Figure 2, there are two main absorption peaks within the range of $450 \sim 750 \mathrm{~cm}^{-1}$. The peak near $560 \mathrm{~cm}^{-1}$ is the characteristic peak which corresponds to stretching vibration of Ga-N bond in hexagonal GaN $[9,10]$. The peak near $603 \mathrm{~cm}^{-1}$ is caused by the vibrational absorption of substituted carbon in the silicon lattice [11]. The carbon is impurities in the Si substrate. It can be seen that the absorption peak of the $\mathrm{Ga}-\mathrm{N}$ bond becomes stronger and stronger with the increase of annealing temperature. The peak is the strongest when the annealing temperature is $950^{\circ} \mathrm{C}$, showing that the crystallization quality of $\mathrm{GaN}$ is the best at the annealing temperature. On the other hand, it also indicates that the strong peak (002) in Figure 1(c) is not generated by $\mathrm{GaN}$ alone. The absorption peak of $\mathrm{Ga}-\mathrm{N}$ bond has a red shift with the increase of annealing temperature. This is due to the increase of the grain size, the decrease of surface tension and elongation of Ga-N bond length, which lead to the decreases of intrinsic vibration frequency of Ga-N bond.



Figure 2. FTIR spectra of unannealed GaN with $\mathrm{ZnO}$ buffer layer (a), ammoniated at $850^{\circ} \mathrm{C}\left(\right.$ b), $900^{\circ} \mathrm{C}(\mathrm{c})$ and $950^{\circ} \mathrm{C}(\mathrm{d})$.

\section{3. $P L$}

Figure 3 is the photoluminescence spectrum (PL) of the sample excited by Xe lamp $(\mathrm{K}=280 \mathrm{~nm})$ at room temperature. It can be seen that there are a strong Photoluminescence peak at $367 \mathrm{~nm}$ and two relatively weak ones at 416 and $437 \mathrm{~nm}$. The luminous peak at $367 \mathrm{~nm}(3.39 \mathrm{ev})$ corresponds to the intrinsic excitation of $\mathrm{GaN}$ at room temperature [12]. The luminescence peak at $437 \mathrm{~nm}(2.84 \mathrm{eV})$ is caused by the radiative transition from the conduction band to the deep acceptor level [13]. However, the luminescence peak at $416 \mathrm{~nm}(2.99 \mathrm{eV})$ is a relatively rare purple peak, which may be related to the $\mathrm{Zn}$ atoms diffused into the $\mathrm{GaN}$ lattice, and its detailed luminescence mechanism needs to be further studied. With the increase of annealing temperature, the positions of the three 
luminescent peaks did not change, but the luminous intensity increased obviously. This is because atoms will be rearranged to reduce the interface energy at a high annealing temperature [14]. Thus grains with good crystallinity will be formed in $\mathrm{GaN}$ films, which affect the luminous characteristics of the films.



Figure 3. PL spectra of GaN with $\mathrm{ZnO}$ buffer layer ammoniated at $850^{\circ} \mathrm{C}$, $900^{\circ} \mathrm{C}$ and $950^{\circ} \mathrm{C}$.

\subsection{SEM}

Figure 4 shows the SEM images of GaN thin films with magnification of $10 \mathrm{~K}$, in which the surfaces of the samples are smooth and the structures are dense. There are many GaN grains on the surface of the film which sizes are relatively uniform. It is because the adsorbed atoms on the surface of GaN film can get enough energy to move to the lowest energy point at a high temperature, thus leading to a film with uniform grain size and dense structure on the macro level [15]. Figure 4(a) shows that the grain size is about $260 \mathrm{~nm}$ at the annealing temperature of $850^{\circ} \mathrm{C}$. Figure $4(\mathrm{~b})$ and (c) show that grain size increases with the increase of the annealing temperature. The grains are in the process of agglomeration at the annealing temperature of $900^{\circ} \mathrm{C}$, so their grain boundary is fuzzy. When the annealing temperature reaches $950^{\circ} \mathrm{C}$, the grain boundary is clear and the grain size is about $500 \mathrm{~nm}$. It is shown that Si-based GaN films prepared with $\mathrm{ZnO}$ as buffer layers have a fine crystallization quality at the annealing temperature of $950^{\circ} \mathrm{C}$.
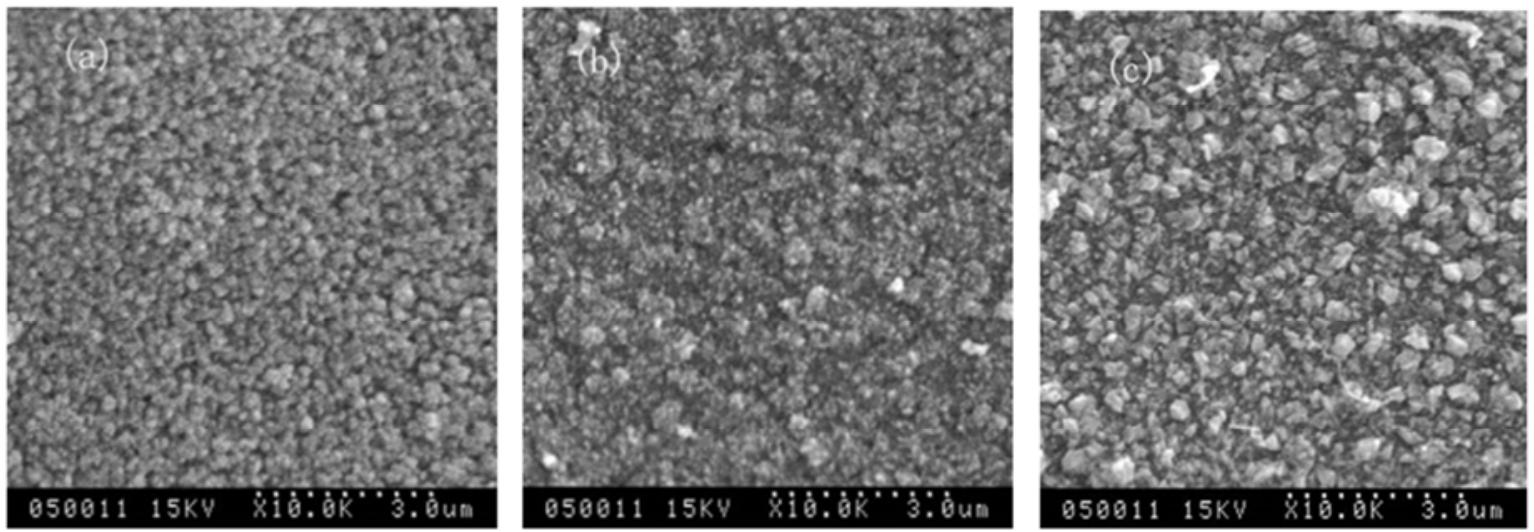

Figure 4. SEM images of GaN with ZnO buffer layer annealed at $850^{\circ} \mathrm{C}(\mathrm{a}), 900^{\circ} \mathrm{C}(\mathrm{b})$ and $950^{\circ} \mathrm{C}(\mathrm{c})$.

\section{Conclusion}

In summary, GaN thin films with good crystallization were successfully prepared on $\mathrm{ZnO} / \mathrm{Si}$ substrates by $\mathrm{RF}$ magnetron sputtering at the annealing temperature of $950^{\circ} \mathrm{C}$, which have hexagonal wurtzite and prefer orientation of $\mathrm{c}$ axis. XRD patterns, FTIR spectra, PL spectra and SEM images showed that $\mathrm{GaN}$ films prepared with $\mathrm{ZnO}$ as buffer layer possess much better crystallization than those without buffer layer at the same annealing temperature of $950^{\circ} \mathrm{C}$. The results show that $\mathrm{ZnO}$ buffer layer greatly improves the crystalline quality of $\mathrm{GaN}$ film because $\mathrm{ZnO}$ and $\mathrm{GaN}$ have the same lattice structure with similar lattice parameters.

\section{Acknowledgements}

This study was supported by National key research and development program, China (2018YFC1707104) and Shandong Provincial Natural Science Foundation, China
(ZR2015FQ004).

\section{References}

[1] Hamdani F, Yeadon M, Dav id J S, et al. Microstructure and optical properties of epitaxial $\mathrm{GaN}$ on $\mathrm{ZnO}(001)$ grown by reactive molecular beam epitaxy. J. Appl Phys. Vol. 83, No. 2, 1998, pp. 983- 990.

[2] Someya T, Wener R, Forchel A, et al. Room temperature lasing at blue wavelengths in gallium nitride microcavities. Science. Vol. 285, 1999, pp. 1905- 1906.

[3] Mahammad S N, Salvador A A, Morkoc H. Emerging gallium nitride based devices. Proceeding s of the IEEE. Vol. 83, No. 10, 1995, pp. 1306- 1355.

[4] Xiaoyu Tan, Xiaoli J, Tongbo W, et al. Investigation of pattern-orientation on stress in GaN grown on $\mathrm{Si}$ (111) substrate in lateral confinement epitaxy. Superlattices and Microstructures. Vol. 122, 2018, pp. 336-342. 
[5] Kim H W, Kim N H. Preparation of GaN films on $\mathrm{ZnO}$ buffer layers by rf magnetron sputtering. Applied Surface Science. Vol. 236, No. 1-4, 2004, pp. 192- 197.

[6] Goldberger J, He R, Yanfeng Z, et al. Single-crystal gallium nitride nanotubes. Nature. Vol. 422, No. 6932, 2003, pp. 599-602.

[7] Haiyong G, Huizhao Z, Chengshan X, ea al. Synthesis of GaN Nanowires Through Ammoniating $\mathrm{ZnO} / \mathrm{Ga}_{2} \mathrm{O}_{3}$ Films on $\mathrm{Si}$ Substrates. Journal of Semiconductors. Vol. 26, 2005, pp. 931935.

[8] B. Y. Man, J. Wei, C. Yang, et al. Buffer layer ZnO-assistant fabrication of c-axis $\mathrm{GaN}$ films by using pulsed laser deposition on Si (111) substrate: annealing effects in ammonia ambience. Applied Physics A. Vol. 96, No. 4, 2009, pp. 827-831.

[9] Jin- Hyo B, Carsten R, Wilson H. MOCVD of BN and GaN thin films on silicon: new attempt of $\mathrm{GaN}$ growth with $\mathrm{BN}$ buffer layer. J. Cryst Growth. Vol. 189/190, 1998, pp. 439- 444.

[10] Baoli L, Huizhao Z, Chengshan X, ea al. Synthesis of GaN nanowires through ammoniating $\mathrm{Ga}_{2} \mathrm{O}_{3} / \mathrm{Nb}$ thin films. Journal of function materials. Vol. 39, 2008, pp. 54- 56.

[11] Yong S, Tatsuro M, Nobuo S. Outdiffusion of the excess carbon in $\mathrm{SiC}$ films into Si substrate during film growth. $J$. Appl Phys. Vol. 84, No. 11, 1998, pp. 6451- 6453.

[12] Shoubin X, Xing Z, Ru H, et al. Effects of the sputtering time of $\mathrm{ZnO}$ buffer layer on the quality of $\mathrm{GaN}$ thin films. Applied Surface Science. Vol. 254, No. 21, 2008, pp. 6766-6769.

[13] Xianglin L, Lianshan W, Dacheng L, et al. Properties of Low-Temperature-Deposited GaN Buffer Layers. Journal of Semiconductors. Vol. 20, No. 8, 1999, pp. 633-638.

[14] Haoxiang Z, Zhizhen Y, Huanming L, ea al. Photoluminescene spectra of $\mathrm{GaN}$ epilayer grown on Si substrate. Semiconductor Optoelectronics. Vol. 20, No. 2, 1999, pp. 120- 122.

[15] Shoubin X, Xing Z, Ru H. Surface morphology of ZnO buffer layer and its effects on the growth of GaN films on Si substrates by magnetron sputtering. Applied Physics A. Vol. 94, 2009, pp. 287-291. 